Available online on 15.01.2020 at http://jddtonline.info
Open Access to Pharmaceutical and Medical Research
unrestricted non-commercial use, provided the original work is properly cited

Open@ Access

Research Article

\title{
Formulation and evaluation of chewable tablets of Desloratadine prepared by aqueous and non-aqueous techniques
}

\author{
Abbas Muhammad ${ }^{1 *}$, Abbas Musharraf ${ }^{2}$, Tariq Fatima ${ }^{3}$, Yasin Rabiya ${ }^{4}$, Nabeel Muhammad 5 \\ ${ }^{1 *}$ Assistant Professor, Islam College of Pharmacy, Sialkot, Pakistan \\ ${ }^{2}$ Lecturer, Lahore Pharmacy College, Lahore, Pakistan \\ ${ }^{3}$ Student, College of Pharmacy, University of Sargodha, Sargodha, Pakistan \\ ${ }^{4}$ Student, Lahore Pharmacy College, Lahore Pakistan
}

\begin{abstract}
In the modern era, chewable tablets are preferred over conventional dosage forms by pediatric, geriatric and bedridden patients due to difficulty in swallowing, lesser amount of water for swallowing medications as well as unable to tolerate the bitter taste of certain drugs Chewable tablets of Desloratadine (DS) were formulated by aqueous and non-aqueous granulation method using water paste and Isopropyl alcohol (IPA) as a wetting agents respectively. Desloratadine is used to treat the symptoms of allergy such as sneezing, wate ry eyes. In the recent research, we have formulated eight trials by various concentrations of excipients. For instance; lactose, talcum, magnesium stearate, blue color, flavor, aspartame, mannitol, avicel 101 and polyvenylpyrollidine (PVP). Pre-compression and post compression parameters (thickness, hardness, friability weight variation and drug content) of the formulations were evaluated. $B_{3}$ was our optimum dosage form because its Hausner's ratio, compressibility index, bulk density, tap density, angle of repose have optimum values i.e. 1.01, 5.1\%, 0.66(g/cc), 0.69(g/cc), $26.1^{\circ}$ respectively and post-compression i.e. thickness, hardness, friability weight variation and drug content have values, $2.9 \mathrm{~mm}, 3.9\left(\mathrm{~kg} / \mathrm{cm}^{2}\right)$, $0.6 \%, 99.5 \%$ respectively. Tablets prepared by wet granulation technique showed reasonable release profile i.e. $100 \%$ within the required time i.e. 2 hours. Moreover, organoleptic evaluation of all formulations were performed.
\end{abstract}

Keywords: Desloratadine, chewable, magnesium stearate, aspartame, compressibility, granulation.

Article Info: Received 09 Nov 2019; $\quad$ Review Completed 11 Dec 2019; $\quad$ Accepted 14 Dec 2019; Available online 15 Jan 2020

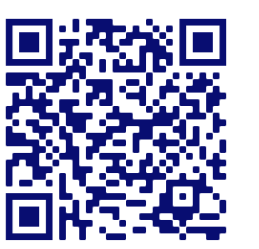

Cite this article as:

Abbas M, Abbas M, Tariq F, Yasin R, Nabeel M, Formulation and evaluation of chewable tablets of Desloratadine prepared by aqueous and non-aqueous techniques, Journal of Drug Delivery and Therapeutics. 2020; 10(1):5-10 http://dx.doi.org/10.22270/jddt.v10i1.3796

Muhammad Abbas, Islam College of Pharmacy, Pasrur Road, Sialkot-51040, Pakistan

\section{INTRODUCTION}

Chewable tablets are the tablets which are required to be broken and chewed in between the teeth before ingestion. Some children have difficulty in swallowing especially pediatric, geriatric and bedridden patients.Selection of suitable ingredients during manufacturing a robust solid dosage form is required during development of formulations. The critical step is the selection of appropriate excipients with minimum disintegration time and maximum bioavailability during design of solid dosage form. Chewable tablets are intended to disintegrate smoothly in mouth at a moderate rate either with or without actual chewing. Characteristically chewable tablets have a smooth texture and pleasant taste upon disintegration 1 . Antihistamines are used as first-line therapy for the treatment of allergic rhinitis ${ }^{2}$. At present, most of signs and symptoms of allergic rhinitis are treated by available antihistamines, but they are ISSN: 2250-1177 not measured to be very effective for the management of congestion $^{3}$. Therefore, antihistamines are frequently administered along with decongestant to reduce nasal obstruction. Consumption of antihistamines is minimized due to their adverse effects. For instance, use of diphenhydramine and chlorpheniramine is condensed as compared to new agents i.e. cetirizine and azelastine, however, it may causes sedation and psychomotor impairment ${ }^{4}$. Another newer agents i.e. terfenadine and astemizole have severe adverse effects e.g. persistence of the QTC interval and cardiac arrhythmias 5 . Uses of several antihistamines have also been decreased due to drug and food interactions. For example, plasma concentrations of terfenadine and astemizole may be increased, when these agents are administered concomitantly with cytochrome P450 inhibitors such as; erythromycin and ketoconazole5. It has been suggested that plasma levels of fexofenadine may 
be changed due to simultaneous administration of erythromycin and ketoconazole, which are drug transporters inhibitors or inducer, such as the organic anion transport polypeptide (OATP) or P-glycoprotein (P-gp)6. On the other side, serum concentration of cetirizine is decreased when the product is administered with food ${ }^{5}$. Desloratadine is a new antihistaminic compound, which is active metabolite of loratadine. It is approximately 10 to 20 times more potent at $\mathrm{H}_{1}$-receptor binding than loratadine in-vitro and 2.5 to 4 times more antihistaminic potency in animals 7 . Desloratadine was also shown to have a significantly longer elimination half-life than loratadine ${ }^{8}$.

\section{MATERIALS AND METHODS}

\section{Materials}

Desloratadine (raw material) was gifted by Wimits Pharmaceuticals Pvt Ltd. Lactose, talc, magnesium stearate, mannitol were purchased from Sigma-Aldrich (Germany). Aspartame, PVP, IPA, Avicel 101 were purchased from Midland Scientific Inc.

\section{Methods}

\section{Characterization of drug-superdisintegrants}

Fourier transform infrared spectroscopy was used to find the physicochemical compatibility between the active pharmaceutical ingredient with excepients used in chewable tablets9. In this method, spectra of pure drug (Desloratadine) and excipients in combination were taken. $\mathrm{KBr}$ press $(1 \mathrm{mg}$ of sample in $300 \mathrm{mg} \mathrm{KBr}$ ) was used to prepare transparent pallets by applying hydraulic pressure of 8000-20000 psi on a pulverized mixture of sample with $\mathrm{KBr}$. Scanning range of infrared is $4000-400 \mathrm{~cm}^{-1}$ and the resolution was $2 \mathrm{~cm}^{-1}$. Compatibility between drug and excipients were evaluated by comparing their FTIR spectra with reference spectra of pure drug11.

\section{Micromeritic properties of formulation powder blends}

Powder blends were prepared according to the quantity mentioned in Table $\mathbf{1}$ to analyze the flowability and compressibility of desired formulations. Angle of repose, bulk density, tapped density, hausner's ratio, and carr's index was calculated to understand the micromeritic properties of powder blends. Angle of repose demonstrates the flow properties of the powder blend and was determined by funnel method. In this method, Powder blend was filled in the funnel and placed $2 \mathrm{~cm}$ above the smooth surface.
Accurately weighed powder blend was poured from a funnel in such a way that maximum cone height (h) obtained and funnel should not exceed more than $1 \mathrm{~cm}$ above the cone height $(\mathrm{h})^{\mathbf{1 0}}$. Angle of repose was calculated by using the following formula.

$$
\theta=\tan ^{-1}(h / r)
$$

Where "h" is the height and " $r$ " radius of the powder cone.

Apparent bulk density, tapped density was measured by the graduated cylinder method and in $\mathrm{g} / \mathrm{mL}$ and hausner ratio was calculated by using following formula.

Hausner ratio $=$ Tapped density $/$ Bulk density ..... (Eq2)

The extent of compressibility of powder blends was determined by measuring apparent bulk density and tapped density and Carr's index was calculated by following formula.

\section{$C=$ Tapped density - Bulk density/Tapped density $x 100$}

\section{Preparation of chewable tablets}

Chewable tablets of desloratadine were prepared by using aqueous granulation and non-aqueous granulation method.

\section{Aqueous Method:}

In this method, active ingredient i.e. desloradine was mixed with lactose, avicel 101 and mannitol. Add $10 \mathrm{ml}$ of $10 \%$ PVP and mix, until wet damp mass was formed. Then passed damp mass from sieve no.12 and granules were formed. Dry these granules in oven at $50^{\circ} \mathrm{C}$ for 30 minutes. Then mix it with sweetening agent (Mannitol or Aspartame), flavoring agent, coloring agent, magnesium stearate and talc. Tablets were formed by using single punch machine equipped with $15 \mathrm{~mm}$ punch and die ${ }^{11}$.

\section{Non-Aqueous Method:}

In this method, active ingredient i.e. desloradine was mixed with lactose, avicel 101 and mannitol. Add 10\%PVP in isopropyl alcohol solution and formed granules. Dried these granules in hot air oven at $40-50^{\circ} \mathrm{C}$. Then again pass these granules from sieve No. 22. After this, mix it with sweetening agent (Mannitol or Aspartame), flavoring agent, coloring agent, magnesium stearate and talc. Then this mixture was tested for evaluation of the flow properties and made tablets by using single punch machine ${ }^{11}$.

Composition of formulations is shown in the Table 1.

Table 1: Composition of one tablet of different batches

\begin{tabular}{|c|l|c|c|c|c|c|c|c|c|}
\hline \multicolumn{2}{|c|}{ Batches Numbers } & T1 & T2 & T3 & T4 & T5 & T6 & T7 & T8 \\
\hline \multicolumn{2}{|c|}{ Chemical Name } & $\mathbf{( m g )}$ & $\mathbf{( m g )}$ & $\mathbf{( m g )}$ & $\mathbf{( m g )}$ & $\mathbf{( m g )}$ & (mg) & (mg) & (mg) \\
\hline 1 & Desloratadine & 5 & 5 & 5 & 5 & 5 & 5 & 5 & 5 \\
\hline 2 & Lactose & 164.03 & 164.03 & 164.03 & 164.03 & 152.03 & 152.03 & 152.03 & 152.03 \\
\hline 3 & Aspartame & 12 & 12 & - & - & 24 & 24 & - & - \\
\hline 4 & Mannitol & - & - & 12 & 12 & - & - & 24 & 24 \\
\hline 5 & Avicel 101 & 2 & 2 & 2 & 2 & S2 & 2 & 2 & 2 \\
\hline 6 & PVP & 5.3 & 5.3 & 5.3 & 5.3 & 5.3 & 5.3 & 5.3 & 5.3 \\
\hline 7 & Talc & 3.73 & 3.73 & 3.73 & 3.73 & 3.73 & 3.73 & 3.73 & 3.73 \\
\hline 8 & Magnesium & 3.07 & 3.07 & 3.07 & 3.07 & 3.07 & 3.07 & 3.07 & 3.07 \\
& Stearate & & & & & & & & \\
\hline 9 & Blue Color & 0.23 & 0.23 & 0.23 & 0.23 & 0.23 & 0.23 & 0.23 & 0.23 \\
\hline 10 & Flavor & 4.61 & 4.61 & 4.61 & 4.61 & 4.61 & 4.61 & 4.61 & 4.61 \\
\hline 11 & IPA & - & $0.12 \mathrm{ml}$ & - & $0.12 \mathrm{ml}$ & - & $0.12 \mathrm{ml}$ & - & $0.12 \mathrm{ml}$ \\
\hline 12 & Distilled Water & q.s & - & q.s & - & q.s & - & q.s & - \\
\hline
\end{tabular}

Each Tablet contains: Desloratadine USP ............... 5mg Batch Size: 200 Tablets 
Abbas et al

\section{Characterization of prepared tablets}

\section{Tablet Hardness}

It is used to determine hardness of the tablets. It is measured by selection of randomly three tablets from each formulation T1-T8 and placed them horizontally between two arms of digital hardness tester (MH-L Galvano Scientific). Breaking force is applied until the tablet is broken down. Note the value of hardness in $\mathrm{kg} / \mathrm{cm}^{2}$.

\section{Tablet Thickness and Diameter}

It is used to verify thickness and diameter of tablets, place the tablet vertically between two arms of the digital apparatus (Pharma Test Germany) and note the values that appear on the screen of instrument.

\section{Weight variation}

This test is used to determine individual weight variation of tablets from an average weight in order to determine the consistency in uniformity of the batch. From each formulation 20 tablets were selected randomly and weighed on an analytical balance (Shimadzu, Japan). Weight variation was calculated according to British Pharmacopeia specifications.

\section{Friability}

Friability of tablets were analyzed by randomly selecting 10 tablets and placed them in a plastic chamber of Rosch Friabilator. The friabilator drum was rotated at $25 \mathrm{rpm}$ for 4 minutes. The percentage loss in the weight of tablets was calculated by the following formula.

\%age Friability = Initial weight - Final weight $/$ initial weight $\times 100$

\section{Drug content determination}

The assay of randomly selected 10 tablets from each batch was conducted to determine the content of Desloratadine. For this purpose, standard stock solution of pure of desloratadine was prepared and then further serial dilutions $(0.01 \mathrm{mg} / \mathrm{ml}-0.05 \mathrm{mg} / \mathrm{ml})$ were prepared from it. Measure the absorbance of the solution at $248 \mathrm{~nm}$ on UV-visible spectrophotometer (PG instruments Ltd) and distilled water using as blank. Determine drug content by using given equation ${ }^{12}$.
Journal of Drug Delivery \& Therapeutics. 2020; 10(1):5-10

$\%$ age content $=$ absorbance of sample/absorbance of standard x 100

\section{Percentage drug release}

The dissolution test is used to evaluate the release of a drug from its formulation in a desired manner. To perform dissolution test we used Paddle Apparatus. Filled each $900 \mathrm{ml}$ volume with dissolution medium (0.1N HCL) and set the temperature $37^{\circ} \mathrm{C}$. Then placed 1 tablet in each beaker and took sample after different time intervals $(30,60,90$ and 120 minutes) and tested under UV spectrophotometer to find out the percentage of drug dissolved in medium with respect to reference solution i.e. Desloratadine solution ${ }^{13}$.

\section{Organoleptic evaluation:}

It is used to determine the taste of the dosage forms by means of our senses. It includes the macroscopic appearance of the drug, its odor and taste, rarely the sound of its fracture and the appearance of the drug to touch. Took 20 healthy volunteers, having appropriate sense of taste and ask them to chew the tablets and evaluate on the basis of following table ${ }^{\mathbf{1 4}}$.

Specifications of Organoleptic evaluation are shown in the Table 2:

Table 2: Organoleptic evaluation scale

\begin{tabular}{|c|c|}
\hline Category & Scale \\
\hline Very Sweet & 5 \\
\hline Sweet & 4 \\
\hline Neutral & 3 \\
\hline Bitter & 2 \\
\hline Very Bitter & 1 \\
\hline
\end{tabular}

\section{RESULTS}

\section{Characterization of drug-superdisintegrants}

FTIR results of pure drug i.e. Desloratadine and optimum dosage form (B3) had shown that all characteristics peaks of Desloratadine were appeared in B3. It shows that there were no interactions between excipients and desloratadine. Their FTIR spectra as shown in Figure 1.
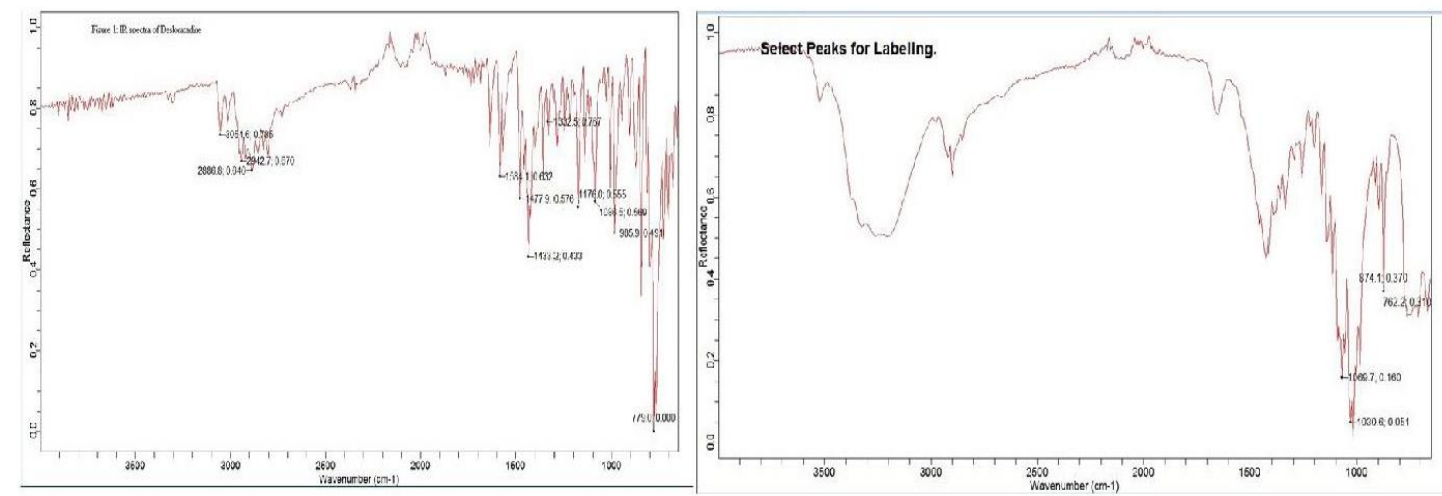

Fig 1: FTIR Spectra 


\section{Micromeritic properties of formulation powder blends}

The bulk and tapped density, compressibility index and Hausner's ratio of all batches were within the range (less than $1 \%$ ) as shown in the Table 3.

Table 3: Micromeritics evaluation of powder blend*

\begin{tabular}{|c|c|c|c|c|c|c|}
\hline Code & $\begin{array}{l}\text { Bulk Density } \\
\text { (g/ml) }\end{array}$ & $\begin{array}{c}\text { Tapped Density } \\
\text { (g/ml) }\end{array}$ & $\begin{array}{c}\text { Carr's Index } \\
\text { (\%) }\end{array}$ & Hausner's Ratio & $\begin{array}{c}\text { Angle Of } \\
\text { Repose } \\
(\Theta)\end{array}$ & Flowability \\
\hline T1 & $0.76 \pm 0.010$ & $0.8 \pm 0.013$ & $5 \pm 0.894$ & $1.05 \pm 0.028$ & $28.5 \pm 1.022$ & Excellent \\
\hline T2 & $0.71 \pm 0.012$ & $0.73 \pm 0.024$ & $2.7 \pm 0.828$ & $1.02 \pm 0.016$ & $27.3 \pm 0.372$ & Excellent \\
\hline T3 & $0.66 \pm 0.021$ & $0.69 \pm 0.058$ & $4.3 \pm 0.161$ & $1.04 \pm 0.013$ & $26.1 \pm 0.920$ & Excellent \\
\hline T4 & $0.72 \pm 0.0360$ & $0.77 \pm 0.014$ & $4.2 \pm 0.974$ & $1.07 \pm 0.097$ & $29 \pm 0.635$ & Excellent \\
\hline T5 & $0.68 \pm 0.012$ & $0.79 \pm 0.007$ & $4.9 \pm 0.501$ & $1.06 \pm 0.094$ & $28.9 \pm 0.375$ & Excellent \\
\hline T6 & $0.73 \pm 0.047$ & $0.73 \pm 0.060$ & $4.8 \pm 0.859$ & $1.05 \pm 0.011$ & $27.6 \pm 0.534$ & Excellent \\
\hline T7 & $0.74 \pm 0.114$ & $0.78 \pm 0.152$ & $4.6 \pm 0.661$ & $1.03 \pm 0.063$ & $28.2 \pm 1.045$ & Excellent \\
\hline T8 & $0.7 \pm 0.013$ & $0.75 \pm 0.033$ & $4.5 \pm 0.706$ & $1.04 \pm 0.013$ & $28.1 \pm 0.870$ & Excellent \\
\hline
\end{tabular}

\section{Characterization of prepared tablets}

All the formulations showed similar thickness. Moreover, friability, hardness, weight variation of all the trials were found to be within the official limits as shown in the Table 4.

Table 4: Characterization of tablets of all formulations

\begin{tabular}{|c|c|c|c|c|c|}
\hline Sr\# & Batch No & $\begin{array}{l}\text { Hardness } \\
\left(\mathrm{kg} / \mathrm{cm}^{2}\right)\end{array}$ & Friability (\%) & $\begin{array}{c}\text { Weight Variation } \\
\text { (\%) }\end{array}$ & $\begin{array}{c}\text { Thickness } \\
\text { (mm) }\end{array}$ \\
\hline 1 & $\mathrm{~T} 1$ & 3.23 & 0.9 & $99.6 \pm 0.32$ & $2.9 \pm 0.2$ \\
\hline 2 & $\mathrm{~T} 2$ & 3.01 & 0.7 & $99.8 \pm 0.99$ & $2.8 \pm 0.2$ \\
\hline 3 & T3 & 2.98 & 0.8 & $99.7 \pm 0.01$ & $2.9 \pm 0.2$ \\
\hline 4 & $\mathrm{~T} 4$ & 4.5 & 0.9 & $98.9 \pm 0.14$ & $2.8 \pm 0.2$ \\
\hline 5 & T5 & 4.3 & 0.8 & $100.2 \pm 0.65$ & $2.8 \pm 0.2$ \\
\hline 6 & T6 & 3.2 & 0.9 & $99.6 \pm 0.74$ & $2.9 \pm 0.2$ \\
\hline 7 & $\mathrm{~T} 7$ & 4.1 & 0.8 & $99.8 \pm 0.41$ & $2.9 \pm 0.2$ \\
\hline 8 & T8 & 3.9 & 0.7 & $99.9 \pm 0.11$ & $2.9 \pm 0.2$ \\
\hline
\end{tabular}

\section{Percentage content of prepared tablets}

The assay of drug was performed using UV-Spectrophotometer at wavelength $280 \mathrm{~nm}$, using $0.1 \mathrm{~N} \mathrm{HCl}$ as blank solution. All the formulations were within the specification (95-105\%) as per USP. The B3 is considered as more optimized formulation as shown in the Table 5.

Table 5: Percentage content

\begin{tabular}{|c|c|c|}
\hline Sr\# & Batch No & Percentage purity (\%) \\
\hline 1 & T1 & 97.45 \\
\hline 2 & T2 & 96.1 \\
\hline 3 & T3 & 99.2 \\
\hline 4 & T4 & 95.2 \\
\hline 5 & T5 & 96.3 \\
\hline 6 & T6 & 97.08 \\
\hline 7 & T7 & 97.09 \\
\hline 8 & T8 & 95 \\
\hline
\end{tabular}




\section{Percentage drug release}

Percentage cumulative drug release of all 8 formulations of Desloratadine chewable tablets were under the specification as shown in the Table 6 and Figure 2.

Table 6: Release Profile all formulations (\%)

\begin{tabular}{|c|c|c|c|c|c|}
\hline Sr\# & Batch No & $\begin{array}{c}\text { Time(30mins) } \\
\text { \%drug }\end{array}$ & $\begin{array}{c}\text { Time(60mins) } \\
\text { \% drug }\end{array}$ & $\begin{array}{c}\text { Time(90mins) } \\
\text { \% drug }\end{array}$ & Time(120) \% drug \\
\hline 1 & T1 & 75 & 85 & 90 & 94 \\
\hline 2 & T2 & 78 & 81 & 89 & 95 \\
\hline 3 & T3 & 84 & 89 & 89 & 96 \\
\hline 4 & T4 & 72 & 89 & 91 & 93 \\
\hline 5 & T5 & 80 & 83 & 91 & 92 \\
\hline 6 & T6 & 79 & 88 & 95 & 92 \\
\hline 7 & T7 & 81 & 89 & 94 & 90 \\
\hline 8
\end{tabular}

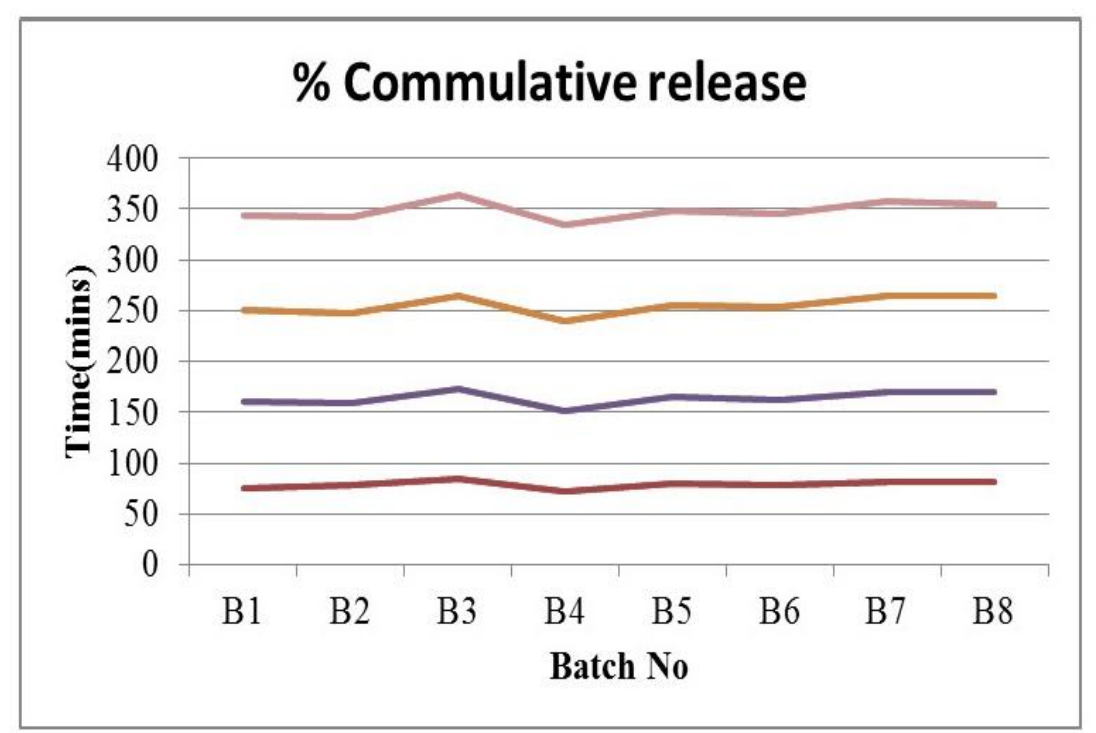

Fig 2: Percentage cumulative drug release of 8 formulations of Desloratadine chewable tablets

\section{DISCUSSION}

\section{Characterization of drug-superdisintegrants}

FTIR spectra of active pharmaceutical ingredient showed the main characteristic peaks between $500-1700 \mathrm{~cm}^{-1}$. The figure shows also alkene ( $\mathrm{C}=\mathrm{C}$ stretch (conjugated)) at 1610 $1640 \mathrm{~cm}^{-1}$, imines (R2C=N-R stretch) at 1640-1690 cm-1, aromatic ( $\mathrm{C}=\mathrm{C}$ stretch) at $1475 \mathrm{~cm}^{-1}$ and $1600 \mathrm{~cm}^{-1},(\mathrm{C}-\mathrm{H}$ stretch) at $3000-3020 \mathrm{~cm}^{-1}$, alkanes (C-H stretch) at 2800 $2950 \mathrm{~cm}^{-1}$, and amines (N-H bend) 3300-3500 $\mathrm{cm}^{-1}$. Characteristic peaks of pure drug appeared in all formulations indicates the absence of any interaction with the excipients material. Since there was no disappearance or change in position of the absorption bands characteristic for the drug, which demonstrates the compatibility between active ingredient and excepients used during formulation of chewable tablets with aqueous and non- aqueous techniques.

\section{Micromeritic properties of formulation powder blends}

The compressibility index for all the formulations was found to be within the range $2-5$, which indicates the excellent properties, the flow properties were further analyzed by determining the angle of repose, which were within the range of 28 to $30^{\circ}$. The Hausner's ratio for all the granules formulated are less than $2 \%$, indicating free flow property. B3 was our optimum dosage form on the basis of bulk density, tapped i.e. $0.71,0.81$ respectively as shown in the Table 3.

\section{Characterization of prepared tablets}

Tablets from different formulations showed hardness in the range of $2.98-3.9 \mathrm{Kg} / \mathrm{cm} 2$.The friability value is less than $1 \%$ all formulations were well within the range.

All batches passed the USP requirement in terms of weight variation and drug uniformity as shown in the Table 4.

\section{Organoleptic evaluation of tablets}

The Studies have shown that taste of formulations have been efficiently masked especially the tablets prepared by aqueous granulation method as shown in the Figure 3. 


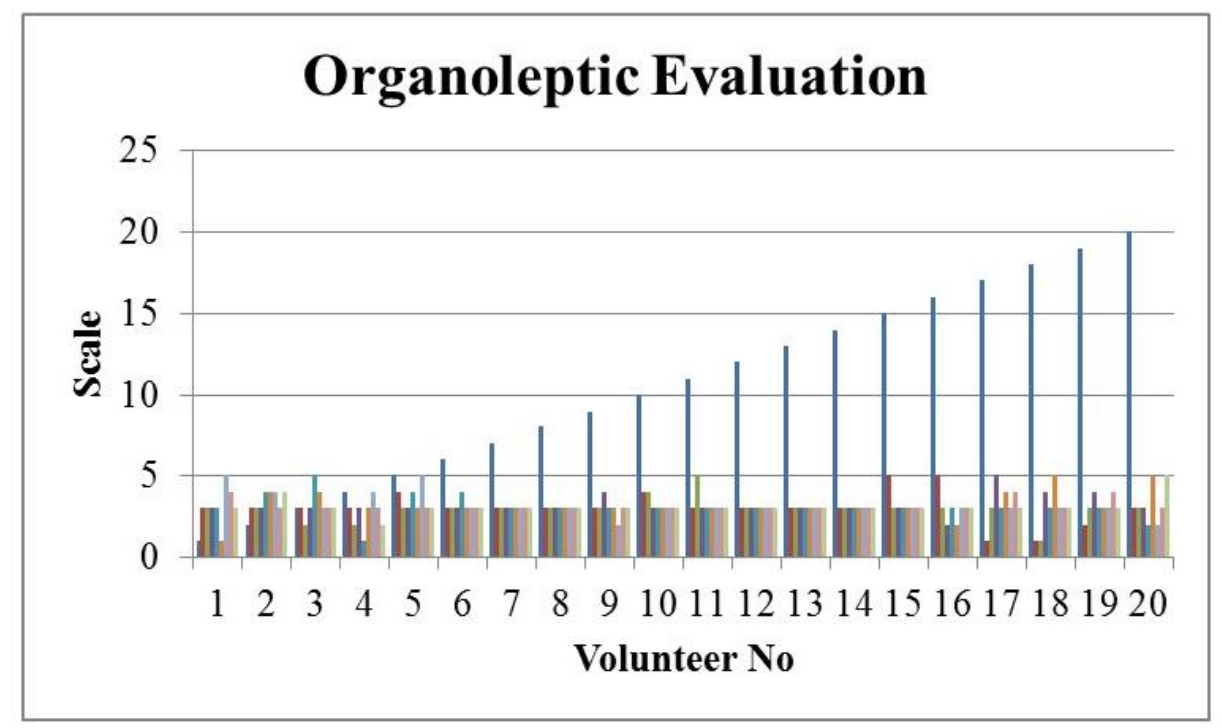

Fig 3: Taste of tablets efficiently masked

\section{CONCLUSION}

From the recent research, it is concluded through FTIR studies that there was no interaction between active pharmaceutical ingredient and excipients, so the drug is compatible with other excipients. Granules showed excellent flow properties and micromeritics parameters of granules were found within official limits. The compressibility index for all formulations was found to be within the range 2-5. The formulated dosage form did not exhibit any sticking, capping, edging, lamination and other defects. Post compression parameters such as hardness, thickness, friability and dissolution time were according to specifications. Dissolution rates of chewable tablets prepared by aqueous granulation technique were better than tablets prepared by non-aqueous techniques.

\section{CONFLICT OF INTEREST}

Authors have no conflict of interest to report.

\section{ACKNOWLEDGEMENT}

Authors like to acknowledge Lahore Pharmacy College for providing their research facilities to conduct this project.

\section{REFERENCES}

1. Udaykumar $M$ et al: Fast Dissolving Tablets: New Fangled Drug Delivery System, A Comprehensive Review. International Journal of Research in Drug Delivery, 2012; 2(3):15-18.

2. Dykewicz MS et al:Diagnosis and management of rhinitis: complete guidelines of the Joint Task Force on Practice Parameters in Allergy, Asthma and Immunology. Annals of Allergy, Asthma \& Immunology, 1998; 81(5):478-518.

3. Van CP et al: Consensus statement on the treatment of allergic rhinitis. Allergy, 2000; 55(2):116-134.

4. Gonzalez M and Estes K. Pharmacokinetic overview of oral second-generation $\mathrm{H} 1$ antihistamines. International journal of clinical pharmacology and therapeutics, 1998; 36(5):292-300.
5. Geha RS and MeltzerEO. Desloratadine: a new, nonsedating, oral antihistamine. Journal of Allergy and Clinical Immunology, 2001; 107(4):751-762.

6. Cvetkovic M et al: OATP and P-glycoprotein transporters mediate the cellular uptake and excretion of fexofenadine. Drug metabolism and disposition, 1999; 27(8):866-871.

7. Kreutner W et al: Preclinical Pharmacology of Desloratadine, a Selective and Nonsedating Histamine H1 Receptor Antagonist2nd Communication: Lack of central nervous system and cardiovascular effects. Arzneimittelforschung, 2000; 50(05):441-448.

8. Affrime $M$ et al: A pharmacokinetic profile of desloratadine in healthy adults, including elderly. Clinical pharmacokinetics, 2002; 41(1):13-19.

9. Lakshmanan S and PandeyM. Analysis of startup oscillations in natural circulation boiling systems. Nuclear Engineering and Design, 2009; 239(11):2391-2398.

10. Nazir T. Extended Release Orally Disintegrating Dosage Forms are Potential Techniques to Deliver and Maintain the Therapeutic Ranges of Plasma Drug Concentrations. J App Pharm, 2015; 7:001.

11. Kandi M et al: Formulation and Evaluation of Chewable Tablet of Metformin $\mathrm{HCl}$ Using Stevia by Different Techniques. International Journal of PharmTech Research, 2013; 5(3):1364-1372.

12. Radke R, JadhavJ and ChajeedM. Formulation and evaluation of orodispersible tablets of baclofen. Int J Chem Tech Res, 2009; 1(3):517-21.

13. Chandrasekaran A et al: Post market in vitro equivalency evaluation of paracetamol tablets in kedah, Malaysia. Int J Pharm Sci Nanotech, 2011; 4(2):1403-1407.

14. Etman MA et al: Formulation of Desloratadine Oral Disintegrating Tablets. Journal of Applied Pharmaceutical Science, 2014; 4(11):054-061. 